\title{
Corrosion behaviour of solar reflector coatings on AA 2024T3 - an electrochemical impedance spectroscopy study
}

\author{
C. Siva Kumar ${ }^{a}$, V. Shankar Rao ${ }^{\text {b }}$, V.S. Raja ${ }^{\text {, }}$, \\ A.K. Sharma ${ }^{c}$, S.M. Mayanna ${ }^{\mathrm{a}, *}$ \\ a Department of Chemistry, Central College Campus, Bangalore University, Bangalore 560 001, India \\ ${ }^{\mathrm{b}}$ Corrosion Science and Engineering Program, IIT Bombay, Powai, Mumbai 400 076, India \\ c Thermal Process Section, ISRO Satellite Centre, Bangalore 560 017, India
}

Received 4 July 2000; accepted 27 April 2001

\begin{abstract}
Electrochemical impedance spectroscopy in the $100 \mathrm{kHz}-5 \mathrm{mHz}$ frequency range was applied to the study of corrosion behaviour of solar reflector coatings on AA 2024 exposed to $3.5 \% \mathrm{NaCl}$ solution. Solar reflector coatings were obtained by sulphuric acid anodization of the alloy in presence of oxo-anions of molybdenum or vanadium. Corrosion behaviour of the oxide films was evaluated by determining the film resistance and capacitance values with exposure time. Comparison of the results reveals that, vanadium addition confers better barrier properties and corrosion resistance than molybdenum additions. Analysis using damage function based on the impedance at $100 \mathrm{mHz}$ shows that solar reflector coatings have improved corrosion behaviour than normal sulfuric acid anodized oxide films on AA 2024. (C) 2002 Elsevier Science Ltd. All rights reserved.
\end{abstract}

Keywords: AA 2024; Electrochemical impedance spectroscopy; Passivation; Thermal control

\section{Introduction}

In space technology, optical solar reflector (OSR) and white paint with requisite optical properties (solar absorptance; $\alpha \leqslant 0.20$ : infrared emittance; $\varepsilon \geqslant 0.80$ ) are

\footnotetext{
${ }^{*}$ Corresponding author.

E-mail address: smm@eth.net (S.M. Mayanna).
} 
being used for thermal control applications [1,2]. However, these materials have limited applications in space mission [2]. Solar reflector coatings $(\alpha=0.16, \varepsilon=0.80)$ on high strength aluminium alloy (AA 2024T3) were developed as suitable alternatives, by anodizing the alloy in sulphuric acid containing metal oxo-anions $[2,3]$. Oxo-anions were used to improve the corrosion behaviour of the alloy [4].

Electrochemical impedance spectroscopy (EIS) has become a powerful tool in understanding the chemical stability of oxide film formed on aluminium and its alloys [5]. Owing to the advantages of this technique, corrosion studies [6] and EIS are inevitably bound together, as documented by the increasingly large number of investigations applying this technique [7,8]. In the present communication, EIS studies on the corrosion behaviour of the coatings obtained during anodization of AA $2024 \mathrm{~T} 3$ in sulphuric acid containing molybdate and vanadate anions are presented.

\section{Experimental}

AA 2024T3 (Cu 4.5, Mg 1.5, Mn 0.6, Si 0.5 max., Fe 0.5 max., Cr 0.1 max., Ti 0.1 max., balance $\mathrm{Al}, \%$ by wt.) samples $\left(4 \mathrm{~cm}^{2}\right)$ were pre-cleaned and processed for anodizing as described earlier [2]. Anodic oxide films were obtained in sulphuric acid $(200 \mathrm{ml} / \mathrm{l})$ medium containing lactic acid $(28 \mathrm{ml} / \mathrm{l})$, and glycerol $(16 \mathrm{ml} / \mathrm{l})$ with a definite concentration $(0.04 \mathrm{M})$ of either sodium molybdate $(\mathrm{M})$ or ammonium metavanadate $(\mathrm{V})$. Solutions were prepared using AR grade chemicals and distilled water. Anodization was carried out at $25^{\circ} \mathrm{C}$ and $1.35 \mathrm{~A} / \mathrm{dm}^{2}$ current density $(\sim 10 \mathrm{~V})$ for $20 \mathrm{~min}$ followed by hydrothermal sealing. A sealing time of $t_{\mathrm{s}}=3 \mathrm{~min} / \mu \mathrm{m}$ of the oxide film was used to suffice perfect sealing.

Impedance measurements were carried out in unstirred $3.5 \% \mathrm{NaCl}$ solution at $25^{\circ} \mathrm{C}$. A three-neck cell set-up was used for EIS measurement [9]. A platinum foil of large surface area and a saturated calomel electrode (SCE) were used as counter and reference electrodes respectively. The anodized specimens were masked with an epoxy resin to expose $1 \mathrm{~cm}^{2}$ area to the test solution.

EIS experiments were carried out using EG\&G PARC 273 potentiostat and a solatron 1255 frequency response analyser driven by m388 software. Ten millivolt potential amplitude was applied to the electrode in the frequency range $5 \mathrm{mHz}<$ $f<100 \mathrm{kHz}$. Impedance data were collected at the open-circuit potential during exposure to the test solution for periods up to 14 days.

\section{Results and discussion}

The impedance behaviour of sulphuric acid anodization (SAA)-AA 2024T3 samples, anodized in presence of either $(\mathrm{M})$ or $(\mathrm{V})$ was studied in $3.5 \% \mathrm{NaCl}$ solution under both sealed and unsealed conditions. The results are presented in Bode coordinates (Figs. 1 and 2 ) for various immersion periods $\left(t_{\text {corr }}\right)$. The shapes of these spectra were similar to those obtained for normal SAA-AA 2024 [10,11]. It is known that the high frequency region of the impedance spectra reflects the properties of the 

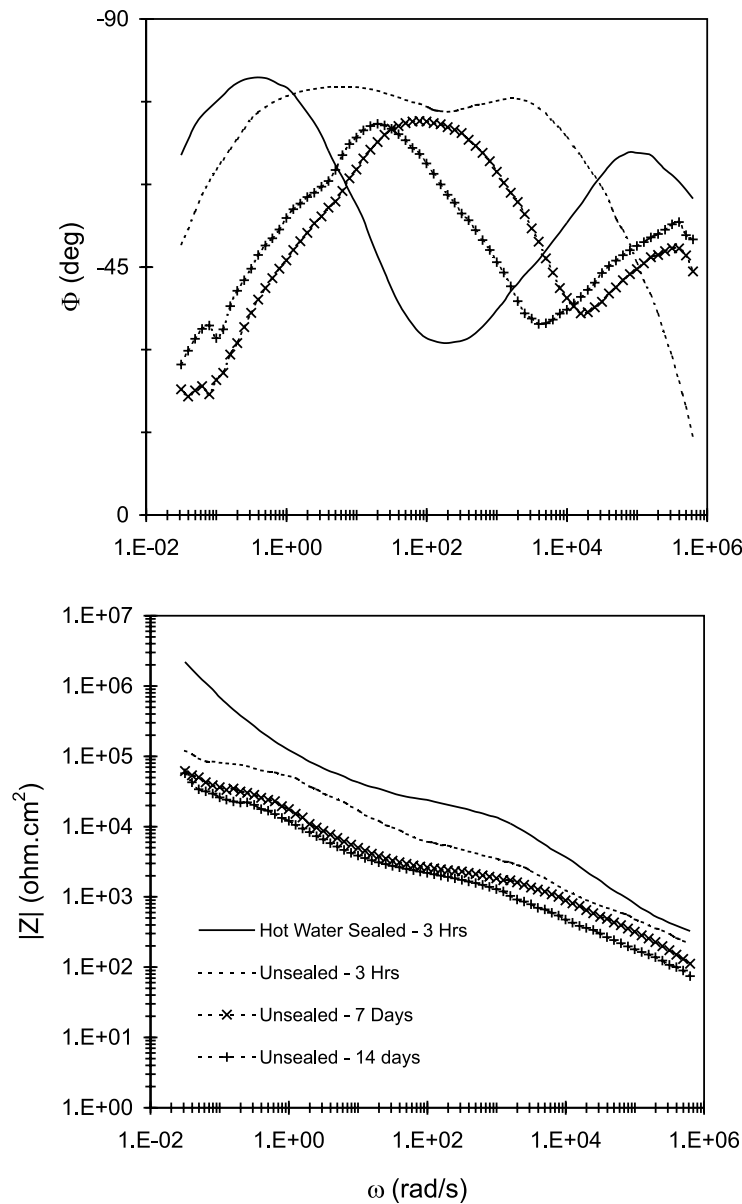

Fig. 1. Bode plots for sealed and unsealed (V) treated samples as a function of $t_{\text {corr }}$.

porous layer, while the properties of the barrier layer are associated with the low frequency region [10]. The impedance behaviour of the oxide film was characterized using the physical properties of these layers. The mean values of capacitance, $C$ and resistance, $R$ in parallel were used to describe their di-electric and electronic behaviour.

The high $\omega_{\max }$ of $(\mathrm{V})$ treated samples infer the capacitive behaviour of the film. In terms of corrosion resistance, this should offer better corrosion performance than (M) treated samples. Continued exposure to $\mathrm{NaCl}$ solution damages the film as is evident from the shifting of $\omega_{\max }$ with time. The values of capacitance $\left(C_{\mathrm{p}}, C_{\mathrm{b}}\right)$ and resistance $\left(R_{\mathrm{p}}\right)$ of the porous (p) and barrier (b) layers are summarized in Table 1. These values for the sealed oxide film are of the order $\mu \mathrm{F} / \mathrm{cm}^{2}, \mathrm{nF} / \mathrm{cm}^{2}$ and $10^{5} \Omega \mathrm{cm}^{2}$ respectively, which indicates adequate sealing quality of the oxide film [12]. 

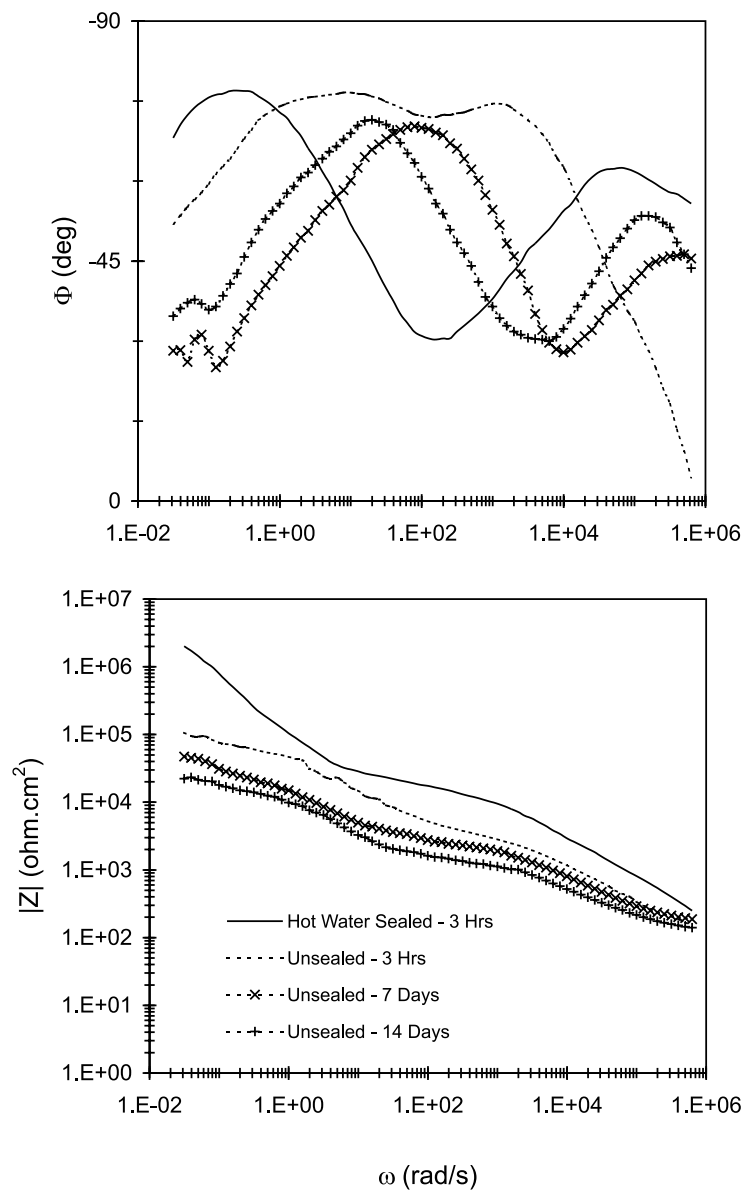

Fig. 2. Bode plots for sealed and unsealed (M) treated samples as a function of $t_{\text {corr }}$.

Table 1

Circuit parameters: unsealed ( $t_{\text {corr }}$ in days)

\begin{tabular}{llllllll}
\hline \multirow{2}{*}{$\begin{array}{l}\text { Circuit } \\
\text { parameters }\end{array}$} & V-treatment & & & & M-treatment \\
\cline { 2 - 3 } & $3 \mathrm{~h}$ & 7 & 14 & & $3 \mathrm{~h}$ & 7 & 14 \\
\hline$R_{\mathrm{p}}\left(\times 10^{4} \Omega \mathrm{cm}^{2}\right)$ & $0.54(2.04)$ & 0.08 & 0.07 & & $0.45(1.58)$ & 0.08 & 0.06 \\
$C_{\mathrm{p}}\left(\mathrm{nF} / \mathrm{cm}^{2}\right)$ & $6760(831)$ & 15135 & 31622 & & $9550(1445)$ & 21379 & 44668 \\
$C_{\mathrm{b}}\left(\mu \mathrm{F} / \mathrm{cm}^{2}\right)$ & $19.3(8.5)$ & 57.5 & 81.3 & & $21.6(9.6)$ & 65.7 & 98.4 \\
\hline
\end{tabular}

The values for the sealed specimens are provided in the parentheses.

The increase in $C_{\mathrm{p}}$ and decrease in $R_{\mathrm{p}}$ values observed with $t_{\text {corr }}$ can be attributed to the dissolution of the porous layer. Occurrence of a second phase angle peak and 


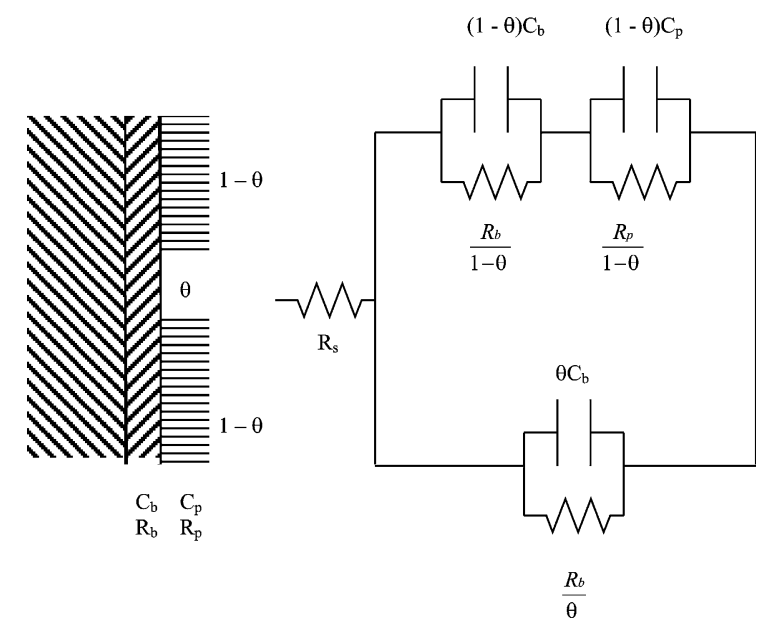

Fig. 3. Model and EC for corrosion damage to porous oxide films - passive pit model $\left(R_{\mathrm{s}}=1 \Omega\right.$; $\left.R_{\mathrm{p}}=10^{5} \Omega ; R_{\mathrm{b}}=10^{9} \Omega ; C_{\mathrm{p}}=1 \mathrm{nF} ; C_{\mathrm{b}}=1 \mu \mathrm{F} ; \theta=0.05\right)$.

the increase in impedance without reaching a definite dc limit are features typical for pitting processes and the spectra can be fitted to the passive-pit model for $\mathrm{Al}$ alloys [10]. An equivalent circuit (EC) that reproduce the impedance behaviour of porous oxide films is proposed (Fig. 3) qualitatively. In the circuit, $\theta,(1-\theta), R_{\mathrm{b}}$ and $R_{\mathrm{s}}$ denote the fraction of pitted surface, fraction of unaltered surface, barrier layer resistance and the solution resistance respectively. A value of $\theta=0.05$ fits the experimental data with the proposed model.

\subsection{Barrier layer characteristics}

The barrier layer thickness $\left(d_{\mathrm{b}}\right)$ can be calculated using the relation:

$$
d_{\mathrm{b}}=r_{\mathrm{a}} E_{\mathrm{a}}
$$

where $r_{\mathrm{a}}$ is unit barrier layer thickness $\left(1.0-1.4 \mathrm{~nm} / \mathrm{V}\right.$ for SAA) and $E_{\mathrm{a}}$ the voltage applied $(10 \mathrm{~V}) . C_{\mathrm{b}}$ is related to the dielectric properties of the film through the expression:

$$
C_{\mathrm{b}}=\varepsilon \varepsilon_{0} A_{\mathrm{g}} d_{\mathrm{b}}^{-1}
$$

where $A_{\mathrm{g}}, \varepsilon$ and $\varepsilon_{0}$ represent the area $\left(1 \mathrm{~cm}^{2}\right)$ of the exposed surface, di-electric constant of alumina (8.5) and permittivity of vacuum $\left(8.854 \times 10^{14} \mathrm{~F} / \mathrm{cm}\right)$ respectively. For a barrier layer thickness of $14 \mathrm{~nm}\left(r_{\mathrm{a}}\right.$ taken as $1.4 \mathrm{~nm} / \mathrm{V}$ for SAA), the capacitance $C_{\mathrm{b}}$ calculated from the Eq. (2) should be $53.7 \mu \mathrm{F}$. The observed $C_{\mathrm{b}}$, however, is lower than this value for both the treatments (Table 1). This may be attributed to either a decrease in the permittivity of the alumina or a raise in thickness of the barrier layer by the passivating action of the anions. 


\subsection{Damage function analysis}

The corrosion behaviour has been characterized by a parameter called damage function $(D)$ [10], which is based on change in the impedance in the low frequency region. The damage function is defined as:

$$
D=\log \left(Z_{0} / Z_{t}\right)_{100 \mathrm{mHz}}
$$

where $Z_{0}$ and $Z_{t}$ are impedance values respectively at $t=0$ and $t=t_{\text {corr }}$ (seven days in the present study) measured at $100 \mathrm{mHz}$. A value of $D=0$ represents perfect corrosion behaviour. Under unsealed condition, the $D$ values for $(\mathrm{M})$ and $(\mathrm{V})$ treated samples were observed as 0.456 and 0.442 respectively. These values infer the improved corrosion behaviour of the treatments when compared to normal SAA-AA 2024 for which $D$ value is reported as 0.60 [10]. The fluctuation of the spectra with exposure time and hence $R_{\mathrm{p}}$, makes it difficult to evaluate $D$ values for hot water sealed samples [11].

\subsection{Mechanism}

The corrosion behaviour of SAA-AA $2024 \mathrm{~T} 3$ with (V) and (M) treatments could be explained by considering the influence of oxo-anions of vanadium and molybdenum [13] $\left(\mathrm{VO}_{3}^{-}, \mathrm{MoO}_{4}^{2-}\right)$ at the metal/oxide interface during anodization. These anions act as passivators by adsorbing at the active sites or flawed regions of the interface [7]. However, the explanation of influence of oxo-anions in the formation of surface films has varied opinion [14]. The adsorbed anions undergo redox reactions and are incorporated into the barrier layer. $\mathrm{VO}_{3}^{-}$ion has high oxidizing power and is smaller when compared to $\mathrm{MoO}_{4}^{2-}$ ion, which helps better healing and strengthening of the oxide film and hence the improved corrosion behaviour.

\section{Conclusion}

Corrosion resistance behaviour of AA 2024T3 samples anodized in sulphuric acid electrolyte, in presence of molybdate and vanadate ions (solar reflector coatings) was investigated in $3.5 \% \mathrm{NaCl}$ medium using EIS. The results of these studies reveal that (1) sealing quality of the hot water sealed anodic oxide film obtained under both treatments are adequate; (2) the (V) treated samples provide better corrosion resistance than (M) treated ones; (3) the damage function evaluated under unsealed conditions reveal superior corrosion behaviour of these coatings in comparison to oxide films obtained from normal SAA.

\section{Acknowledgements}

The authors thank Dr. P.S. Goel, A.V. Patki, H. Narayanamurthy and H. Bhojraj, ISRO Satellite Centre, Bangalore for providing valuable suggestions during 
this investigation. The authors C.S.K. and S.M.M. thank ISRO Satellite Centre, Bangalore and UGC, New Delhi for financial support.

\section{References}

[1] B.N. Agarwal, Design of Geo-synchronous Spacecraft, Prentice-Hall, NJ, 1986.

[2] C. Siva Kumar, S.M. Mayanna, K.N. Mahendra, A.K. Sharma, R. Uma Rani, Appl. Surf. Sci. 151 (1999) 280.

[3] C. Siva Kumar, A.K. Sharma, K.N. Mahendra, S.M. Mayanna, Solar Energy Mat. Solar Cells 60 (2000) 51.

[4] C.J.E. Smith, M.A.H. Hewins, K.R. Baldwin, P.L. Lane, Eurocorr'96, 1996, pp. 8.1-8.4.

[5] J. Hitzig, K. Juttner, W.J. Lorenz, W. Paatsch, Corros. Sci. 24 (1984) 945.

[6] G. Rocchini, Mater. Corros. 54 (1998) 18.

[7] W.A. Badawy, F.M. Al-Kharafi, Corros. Sci. 39 (1997) 681.

[8] K. Bonnel, C. Le Pen, N. Pebere, Electrochimica Acta 44 (1999) 4259.

[9] V.S. Raja, Trans. IIM. 51 (1998) 351.

[10] F. Mansfeld, M.W. Kendig, J. Electrochem. Soc. 135 (1988) 828.

[11] F. Mansfeld, G. Zhang, C. Chen, Plat. Surf. Finishing 84 (1997) 72.

[12] J.A. Gonzalez, V. Lopez, A. Bautista, E. Otero, X.R. Novoa, J. Appl. Electrochem. 29 (1999) 229.

[13] G.E. Thompson, P. Skeldon, K. Shimizu, G.C. Wood, Phil. Trans. Royal Soc. A 350 (1995) 143.

[14] W.C. Moshier, G.D. Devis, Corrosion 46 (1990) 43. 